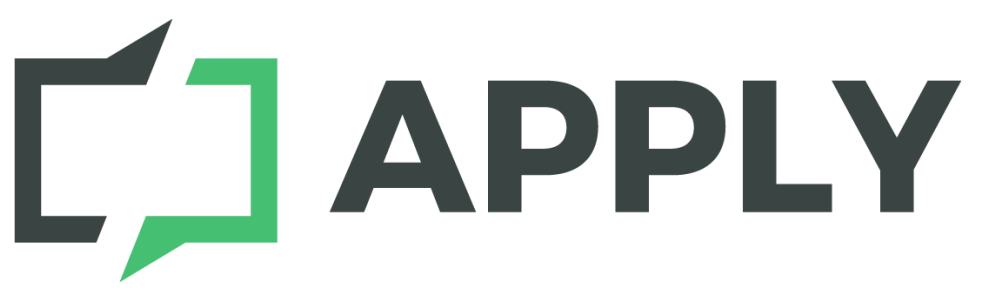

\title{
Goals and functions of public argumentation
}

Lead authors: ${ }^{1,2,3}$ Frank Zenker and ${ }^{4}$ Jan Albert van Laar; ${ }^{1}$ Dpt. of Philosophy, Boğaziçi University, 34342 Istanbul, Turkey; ${ }^{2}$ Int. Center for Formal Ontology, Warsaw U. of Technology, Poland; ${ }^{3}$ Dpt. of Philosophy, Lund University, Sweden; ORCID: 0000-0001-7173-7964; ${ }^{4}$ University of Groningen, Oude Boteringestraat 52, Groningen, The Netherlands

Co-authors: Abreu, P., Nova University of Lisbon, Nova Institute of Philosophy, Lisbon, Portugal;

Bengtsson, M., Roskilde University, Roskilde, Denmark;

Castro, D, University of Groningen, Groningen, The Netherlands;

Cooke, M., School of Philosophy, University College Dublin, Ireland;

Danka, I., Budapest University of Technology and Economics/John von Neumann University, Budapest/Kecskemet, Hungary;

De Cock, B., Université catholique de Louvain, Louvain-la-Neuve, Belgium;

Dutilh Novaes, C., Department of Philosophy, Free University of Amsterdam, The

Netherlands; Arché, University of St. Andrews, Scotland;

Farine, L., University of Neuchâtel, Neuchâtel, Switzerland;

Gâţă, A., Dunărea de Jos University of Galaţi, Galaţi, Romania;

Greco, S., Università della Svizzera italiana (USI), Lugano, Switzerland;

Grossi, D., University of Groningen, Groningen, NL;

Jolić, T., Institute of Philosophy, Zagreb, Croatia;

Lanius, D., Karlsruhe Institute of Technology (KIT), Karlsruhe, Germany;

Lewiński, M., ArgLab, Nova Institute of Philosophy, Universidade Nova de Lisboa, Lisbon, Portugal;

Lumer, C., University of Siena, Siena, Italy;

Łupkowski, P., Adam Mickiewicz University, Poznań, Poland;

Mohammed, D., FCSH, Universidade Nova de Lisboa, Lisbon, Portugal;

Oswald, S., University of Fribourg, Fribourg, Switzerland;

Pichlak, M., University of Wrocław, Wrocław, Poland;

Rast, H., Nova Institute of Philosophy, New University of Lisbon, Lisbon, Portugal;

Ritola, J., University of Turku, Turku, Finland;

Rodríguez-Alcázar, J., University of Granada, Granada, Spain;

Sadek, K., University College Dublin, Dublin, Ireland;

Scott, B. D., Institute of Philosophy, KU Leuven, Leuven, Belgium;

Stojanovic, I., Institut Jean-Nicod, CNRS, DEC, ENS, PSL Research University, Paris, France;

Tindale, C.W., Centre for Research in Reasoning, Argumentation and Rhetoric,

Windsor, Ontario, Canada;

Urbanski, M., Adam Mickiewicz University, Poznan, Poland;

Wagemans, J.H.M., University of Amsterdam, Amsterdam, The Netherlands 


\section{Goals and functions of public argumentation}

Abstract: This position paper of Working Group 2 of the European Network for Argumentation and Public Policy Analysis (COST Action CA17132; https://publicpolicyargument.eu) reviews goals and functions of public argumentation. Drawing on a variety of disciplines, the paper introduces basic distinctions and charts out options. It is meant to guide reflection on the conceptual basis for the Action's subsequent research regarding the analysis, evaluation, and design of public argumentation.

Keywords: apprehension, decision making, function, goal, norm, opinion formation, public argumentation

\section{Introduction}

Studying public argumentation - the exchange, that is, of arguments about public affairs as these occur in public settings - touches upon disciplines and areas of research such as argumentation theory, artificial intelligence, deliberation theory, discourse analysis, linguistics, philosophy of law, political philosophy, rhetoric, social choice theory, and speech communication, amongst others. In argumentation theory, the disciplinary point of departure adopted here, argumentation is typically characterized as a communicative activity aimed at deliberating about, contending with, and inquiring into problems and disagreements by means of exchanging and critically evaluating reasons pro and con.

Questions such as "What is the goal of argumentation in policy making or public controversies?" or "What functions does and should argumentation serve when individuals, small groups or large collectives form their opinions and come to their decisions?" touch upon how society should be organized and how problems and disagreements regarding policy choices should be dealt with. Such questions address the norms that (should) govern public argumentation, norms which this paper approaches indirectly. Drawing on a variety of disciplines, we first describe the goals and functions of public argumentation. (A subsequent paper should address these norms directly.)

Within the APPLY Action, one purpose of an inventory of goals and functions is to support empirical research into the argumentative characteristics of corpora of public argumentation, thereby connecting to research in working group one (WG-1). Another purpose is to guide the design of tools for public argumentation (e.g., e-learning software, disputation frameworks, argument visualization techniques, or measures for aggregating opinions), thus connecting to research in WG-3. A third purpose-indeed WG-2's chief purpose-is to apply this 
inventory when determining the extent to which contributions to an argumentation process facilitate, or hinder, the rational solution (or resolution) of problems or disagreements regarding a public policy issue.

We use 'argumentation' in a broad sense, denoting interpersonal reasoning aimed at resolving, or otherwise inquiring into, differences of opinion or problems. 'Argumentation' thus refers both to the specific acts of arguing and the communicative practices of exchanging such acts. In Section 2, we elaborate on the concept of public argumentation. In Section 3, we list prominent views on the goals and functions of public argumentation concerning opinion formation and decision making at the level of societies and large collectives. Section 4 deals with opinion formation and decision making by individuals and small groups. In Section 5, we complete the inventory by focusing on goals and functions pertaining to understanding and apprehension.

The scholarly story emerging from these sections is coherent up to a point. Diverse philosophically/theoretically-motivated disagreements and divergences remain, which we cannot hope to resolve here, now.

\section{Argumentation theory and public argumentation}

Argumentation theorists deal less with abstract forms of human reasoning and justification as studied in logic and epistemology, than with the use of reasons in understanding and solving practical problems or disagreements. Argumentation theorists develop tools for analysing and evaluating argumentative discourse, including tools for characterising and evaluating modes of presentation (e.g. visual), argumentative styles (e.g. introvert) and argumentative strategies (e.g. non-authoritarian).

In their Handbook of Argumentation Theory van Eemeren and co-authors (van Eemeren et al., 2014) offer a definition of 'argumentation' that emphasizes its communicative and interactional aspects: "[a]rgumentation is a communicative and interactional act complex aimed at resolving a difference of opinion with the addressee" (ibid., 7), such that "argumentation involves putting forward a constellation of propositions the arguer can be held accountable for" (ibid., 5), and "involves an appeal to the addressee as a rational judge who judges reasonable" (ibid., 5-6). This definition gives pride of place to argumentation's function of contributing to the resolution of a difference of opinion.

As a point of departure for this paper, the definition gives precedence to a dialectical stance on the aim of argumentation. This emphasizes the proponent's goal of convincing an opponent who critically tests the proponent's thesis and the arguments forwarded in its favour (Hamblin, 1970; Walton and Krabbe, 1995; van Eemeren and Grootendorst, 2004). Scholars can place different emphases, of course. In rhetorical theories, for instance, the emphasis is on context-sensitive goal of 
persuading often larger, not directly-responding audiences (Perelman and Olbrechts-Tyteca, 1969). In epistemological theories of argumentation, by contrast, the emphasis is on the goal of producing knowledge or justified belief (Goldman, 1994; Lumer, 2005; Biro and Siegel, 2006).

Among the rich terminology to describe public argumentation, perhaps most notable are 'public reason', 'deliberation', and 'justification'. Chambers (2010) has identified three aspects to distinguish public justification from other forms of justification - aspects we now rely on to characterize public argumentation.

First, 'that a justification is public' expresses that it deals with "public things, i.e., laws, constitutions, basic social structure" (ibid., 894). Analogously, public argumentation deals with the acceptance, implementation, or enforcement of law or policy, and thus with the exercise of power. Second, the phrase expresses that "the addressee of the justification is a public at large characterized by pluralism" (ibid., 894). Argumentation is thus public insofar as it addresses a (more or less) general audience, typically consisting of agents bound by the law or policy at issue. Third, it expresses that argument "is presented in public or by citizens acting publicly" (ibid., 894). Thus argumentation is public insofar as it is conveyed in public by persons in their public capacity. In sum, we characterize the practice of public argumentation as: argumentation that is about a public issue (content clause) and that is typically expressed by people in their public capacity, e.g. as citizens or politicians (speaker clause), in an open forum (context clause), while addressing a larger audience whose members are people in their public capacity (addressee clause).

A prototypical instance of public argumentation would thus satisfy all four clauses jointly, while degrees of "public argument or family-and cluster-conceptions of public argumentation can recognize the four clauses as jointly sufficient conditions without having to treat any one condition as necessary. Our characterization of public argumentation thus allows us to be inclusive. An exchange of reasons between judges, for example, even if it occurs behind closed doors, nevertheless becomes an instance of public argumentation if it deals with a public issue, and if it prepares the judges to reach a motivated decision to be shared in public. Or, if a private discussion amongst colleagues about a governmental decision affecting them is instrumental in reaching well-considered opinions about the decision, then this may influence who they vote for in an upcoming public election. Similar cases, at any rate, are no less instances of public argumentation. Because argumentation is expressed in various modes, moreover, an inclusive characterization of public argumentation must also recognize that argumentation finds expression in narratives, in the display of emotions, in visuals, gestures and sounds.

Chambers also discusses the concept of public reasons-i.e., reasons the content of which is "intelligible, accessible, acceptable, or sharable" (ibid., 894). 
Avoiding the requirement that public justifications would involve the exclusive use of public reasons, she suggests that the idea of public reasons provides for a content-oriented angle from which to view public justification, on a par with deliberation as a process-oriented angle. We propose an analogous approach when characterizing public argumentation. After all, a definitional clause requiring reasons to be public in this sense would make the concept of public argumentation unduly restrictive. For instance, it would exclude prima facie "illiberal" argumentative contributions that may narrowly appeal to religious or nationalist values. (Note that our inclusive characterization of public argumentation nevertheless allows adopting restrictive norms by which to evaluate religious or nationalist arguments as suboptimal or even inadmissible.) Further, if core instances of public argumentation are addressed in public and are about something public, then arguers are already strongly incentivized to offer reasons which can be evaluate for their potential to not only be understood, but also accepted — indeed shared — among the widest possible audience(s) addressed.

This position paper is mainly concerned with the goals and functions of the exchange of arguments and criticisms, i.e., with the practice in which public argumentation figures prominently (Mohammed, 2016). (This entails downplaying goals and functions applying to individual agents' acts of arguing such as persuading others, or gaining support for one's policy preferences, for a survey and discussion of which see Walton and Krabbe, 1995; Gilbert, 1997; Patterson, 2011). We view the goals of public argumentation as the proximal outcomes that agents strive to realize by engaging in the practice. Pursuing these goals involves an active effort and a more or less conscious intention. The functions of public argumentation are the argumentative process' typical contributions towards particular social or political processes. Arguers must direct conscious efforts towards realizing these outcomes.

Importantly, arguers do not only create, or reproduce, arguments and criticisms that figure in argumentative exchanges; they also design, or redesign, the institutional contexts of their communication (Jackson, 2015). We therefore include goals and functions of public argumentation that concern an institutional settings's structure (as designed or having evolved) for managing public argumentation.

From a normative perspective, this paper asks: what goals and functions argumentation should serve to be legitimate, justified, or acceptable. The point of advancing an argument, of course, is to provide good reasons for a thesis (e.g., a policy recommendation). Allegedly good reasons, however, may nevertheless lead to mistaken opinions and bad decisions. Argumentation may thus serve us poorly. In fact, some argumentative interactions can be mere charades, allegedly offering good reasons yet really constituting but an exercise of power, intimidation, or bluffing. Further, people may genuinely disagree about the legitimacy of their arguments. What one person finds is a bad argument another may find good; what this person 
perceives as emotional blackmail, a threat, or bribe, another could view as a legitimate form of advocacy. These observations underline both the normative character of the practice of public argumentation, as well as the need for clear ideas about the goals and functions public argumentation should serve.

\section{Collective opinion formation and decision-making}

In settings where (relatively) large collectives seek to form a common opinion, or to arrive at a shared or justified decision, public argumentation serves goals and functions that relate to a decision's legitimacy. If participants to a socio-political setting engage in due reflection about their individual preferences, as well as the available policy options and the extent to which those concerned consider the options justified, then argumentation can serve the function of forming and justifying positive or negative opinions about establishing, or upholding, political or legal decisions (Rawls, 2005; Habermas, 1996; Dryzek \& List, 2003). Whether a collective decision then deals with the general political and legal order or with specific laws and policies, it can always be viewed as receiving its legitimacy from reasons that those whom the decision affects do (or could) accept as a justification, or could least apprehend as such (Benhabib, 1994, 32).

To realize genuinely legitimate decisions, participants must not only arrive at a reason-based decision; the decision should also result from a procedure they themselves accept as valid. As a consequence, argumentative exchanges serve the meta-argumentative quest for finding or designing the norms by which to evaluate contributions to public argumentation as valid or invalid, and as providing or failing to provide genuine justification (Cooke, 2002). (What 'validity' means does strongly depend on one's approach; among the possible meanings are logical, dialectical, rhetorical and epistemic kinds of validity, which can be detailed from a subjective, intersubjective, or objective viewpoint.)

The evaluative norms for a decision's political legitimacy thus include norms for the validity of the argumentative praxis through which legitimacy is established. But since "any procedure [...] can be misinterpreted, misapplied and abused," it follows that "[p]rocedures [alone] can neither dictate outcomes, nor can they define the quality of the reasons advanced in argumentation, nor can they control the quality of the reasoning and rules of logic and inference used by participants" (Benhabib, 1994, 33). (This is one reason to treat purely procedural models of rationality as underdetermining the rationality of a decision-making outcome.)

Which function one assigns to public argumentation can be influenced by one's view on the appropriate role of government. As examples, we briefly discuss republicanism and liberalism. Central to both traditions is the concept of freedom, either-as in republicanism-freedom as non-domination by an arbitrary power (Pettit, 1997), or-as in liberalism—freedom as independence from interference 
with one's actions. Both forms of freedom require fora for public argumentation, where policy proposals and decisions are open to contestation (Lovett, 2018). According to republicanism, both the reasons and the processes of reasoning are public in virtue of dealing with the common good, as opposed to self- or partisan-interests (Sunstein, 1993; Pettit, 1997). This yields two connected functions of public deliberation argument: deliberating on the common good and securing citizens from the arbitrariness exercise of power (Bellamy, 2009; MacCormick, 2005). By contrast, liberalism acknowledges the government's role in protecting citizens from serious violations of their rights (whether natural or positive ones). But instead of focusing on the government's role in cultivating civic virtue and the common good, this tradition places the state at the service of individual citizens: the rule of law must in some way or another be based on the wills of the individual citizens (Wolterstorff, 2012). This requirement can be given a reason-based interpretation in the justification principle: "[a] coercive law $\mathrm{L}$ is justified in a public $\mathrm{P}$, if and only if each individual member $\mathrm{i}$ of $\mathrm{P}$ has sufficient reason( $\mathrm{s}$ ) Ri to endorse L" (Vallier, 2018, 24).

One may treat the required legitimacy as resulting from argumentation in an ideal setting, entirely hypothetical rather than real. Examples are deliberation behind a veil of ignorance (Rawls, 2005), or in an idealized communicative situation (Habermas, 1996). Alternatively, one may treat the bestowment of the required legitimacy as a factual goal, thus linking this goal to argumentation in real-life settings that merely approximate the ideal. Although this brings a contextual, empirical conception of argumentation into play, the evaluative norms can nevertheless still be derived from specific views about an ideal communicative setting. Given a specific non-ideal communicative situation, for instance, one can always ask: what would the ideal of the "unforced force of the better argument" (Habermas, 1996, 541) consist in here?

We can thus view argumentation that bestows legitimacy on decisions as resulting from the exchange of reasons under normative constraints implemented in specifically designed real-life disputations such as deliberative polling or debate (Fishkin, 2009; Manin, 2005). Public argumentation may serve social deliberation processes in the informal public sphere-for instance, it may enhance an exchange in a newspaper's editorial section or in social media (Habermas, 1996) - as well as in the institutionalized public sphere - for instance, it may feed into a courtroom or parliamentary debate. In both cases, public argumentation assists those involved and affected by a decision in arriving at judgements and decisions that address, and potentially withstand, pertinent critical challenges.

Specifically, argumentation may be understood as being instrumental to the ends of deliberation in the informal public sphere when it enables agents to evaluate reasons in terms of their acceptability and intelligibility to the public at large. 
Alternatively, it may be understood as serving deliberation in a more pluralist sense, when it appeals to specific publics (e.g., Roman Catholic citizens, or laborers). A special case are counterpublics (Fraser, 1992), constituted by marginalised groups who hold, express, or push for a common idea, interest, or identity against the tide of the prevailing public opinion.

Besides serving to establish political legitimacy that is (partially) grounded in agreement, argumentation can also serve more directly to produce decisions that are deontically right, or good in a utilitarian sense, or legally or morally just, or ecologically sustainable, and so forth. Rather than attribute these moral functions to argumentation, of course, one can identify such political functions of argumentation as: securing order, providing security, and fostering cooperation by enabling shared decisions whenever agents persistently disagree in matters concerning 'the right,' 'the good,' 'the just,' or 'the ecological' (Williams, 2005; Dryzek, 1983; 2010).

Public argumentation that an orator addresses to a non-responsive mass audience may narrowly serve to bolster the orator's support and power - in which case Chambers speaks of "plebiscitary rhetoric" - or it may amount to "deliberative rhetoric" whenever it encourages addressees to reflect upon an issue at hand (Chambers, 2009). The latter kind is important for large democracies because the exclusive focus on deliberation in small groups (mini-publics) risks falling prey to "participatory elitism" (ibid.). By establishing and strengthening alliances between agents who hold similar social outlooks, or by helping to identify points of agreement on both sides of an issue, rhetoric can generally lead to bonding and bridging between agents. But when left unchecked, it may also serve hierarchical power interests that threaten democratic pluralism (Dryzek, 2010).

Public arguments are important in public accountability practices. Accountability puts public actors under an obligation to justify their conduct, thus controlling power by subjecting it to the rule of public reason (Schedler, 1999). While accountability may be approached from a variety of perspectives (e.g. Mulgan, 2004; Tsai, 2011), there is agreement that actors held accountable should explain and justify their conduct to a forum which can pass a judgment (Bovens et al., 2010). Some forums are designed for that purpose (e.g., audit offices and administrative tribunals); at other times, accountability is exercised by forums that also serve additional purposes (Mulgan, 2000). A parliament, for instance, whether in purposefully designed sessions such as Question Time (Mohammed, 2018) or during a legislative debate or a financial authorisation, turns into the forum which holds an executive accountable. When accountability occurs through public argumentation and an electoral process is provided, the ultimate account-holder who gets to pass judgment thus is the general public (Mulgan, 2004, 24).

Emotions such as fear, anger, pity, or feelings of solidarity may-whether they are displayed verbally, visually or in another presentational mode-fulfill 
argumentative functions such as expressing reasoning in an enthymematic way, or binding the audience to the acceptance of reasons advanced in support of accepting or rejecting a policy. In this respect, visual rhetoric seems especially apt insofar as it can convey the importance and urgency of some normative perspective on a practical issue (e.g., the priority of sustainability over austerity). This may help tilt social deliberation processes towards a resolution (Kjeldsen, 2015).

As part of social deliberation processes, argumentation should enable the formation of collective judgements based on individual judgements and preferences. As Arrow's (1951) impossibility theorem shows, however, if the following four individually reasonable conditions are all satisfied, then it is impossible to always (algorithmically) aggregate agents' individual preferences into a single collective preference order: (i) any level of pluralism can serve as input (i.e., the aggregation procedure holds for a universal domain); (ii) if all agents prefer option A over option $\mathrm{B}$, so does the collective (weak Pareto principle); (iii) any collective preference for option A over B depends only on agent's individual preferences regarding these options (independence of irrelevant alternatives); (iv) no agent determines the joint order regardless of others' preferences (non-dictatorship) (List, 2013).

Moreover, the Gibbard-Satterthwaite theorem shows that no collective choice procedure leading to a single decision is possible, if conditions similar to (i) through (iv) hold together with the condition that agents cannot manipulate the collective decision by expressing false preferences (i.e., if the choice procedure is "strategy-proof"). In principle, deliberation may compensate for relaxing the above conditions, so that one collective preference order (i.e., one social choice) can be aggregated that counts as rational, although fewer than all of the above conditions are satisfied (Dryzek \& List, 2003).

We now list four functions of social deliberation: (1) social deliberation "induces individuals to reveal their preferences and views truthfully" (Dryzek \& List, 2003, 9; Goldman, 1994) for several reasons. First, communication is typically recurrent, so that lying now may be potentially profitable, but can destroy a speaker's credibility later. Second, critical argument is generally a good way of testing the value of information, a purpose that Mercier and Sperber (2011) call the exercise of epistemic vigilance, and for which argumentation may have developed phylogenetically. Third, the "we-frame" of deliberation often lets participants act comparatively more collaboratively than they would otherwise (Dryzek and List, 2003). Insofar as this promotes truthfulness, social deliberation may compensate for no longer demanding choice procedures that are "strategy-proof." Thus, a social choice can be aggregated from individual preferences because individuals by themselves stop manipulating its outcome by expressing false preferences.

(2) Social deliberation may influence individuals' preference profiles via encouraging participants to evaluate policy preferences by first reaching a 
meta-level agreement on some criterion or dimension (e.g., a mutually acceptable generalized interest). If a suitable criterion is found, individuals can be convinced to drop preference orderings that are incoherent relative to the criterion. The resulting set of individual preference orderings then are "single-peaked," that is, they can be ordered 'objectively', for instance on a left-right spectrum. This makes it possible to work around Arrow's impossibility theorem, enabling mechanisms that can democratically aggregate a collective decision from individual preferences (on the Median Voter Theorem, see Black, 1948).

Deliberation can thus be viewed as a procedure to pre-process the inputs of a voting mechanisms, filtering out those inputs that lead to incoherent results. This explains why viewing deliberation from the perspective of deliberative democracy (Elster, 1998) - as a tool to improve the quality of individual inputs to voting mechanisms - has received increasing attention in studies of social choice, often under the description 'epistemic social choice theory' (cf. Pivato, 2019). In situations where no single criterion is available (because the issue is complex and multi-dimensional) public argumentation can serve a similar function by inducing single-peaked profiles for any such criterion or dimension. In addition, it can help individuals in subsequently finding a majority for a middle ground solution, a solution based in bargaining or on an agreed hierarchy of criteria, or it can help to craft new policy options based on an improved understanding of the issue's multidimensional nature (Dryzek \& List, 2003; from a non-technical angle, also see Kock, 2006; 2007).

(3) Social deliberation may induce agreement on the option-set from which a collective can choose, thereby reducing the scope of manipulating the aggregation procedure that arises from introducing false preferences ("agenda setting"). This supports social aggregation even if a violation of the "independence of irrelevant alternatives"-condition is not ruled out in a principled way (Dryzek \& List, 2003).

(4) Insofar as public argumentation brings out how to best compare the intensity of individual preferences - using a utilitarian principle, for example, or a Rawlsian (2005) index of primary goods - it may in the end enable preference-aggregation, and can even lead to a rational collective decision that satisfies all of the conditions discussed above (ibid.).

We finally turn to legal perspectives. Public argumentation may serve the development of valid legal opinions and decisions that are justified either externally if the supporting reasons are correct in the legal setting at hand, or are justified internally if the judgement follows logically from the grounds a legal context requires (Wróblewski, 1971). Enabling a valid legal decisions thus are legal norms, procedures, and institutions - components that a practical discourse in the general sense of an informal public sphere typically lacks (Alexy, 1989). To require legal decisions to be rationally justified (by basing them on general, universalized, 
coherent, accessible, and acceptable norms) makes law relatively predictable and at the same time arguable, i.e., open to reasonable criticism (MacCormick, 2005). In this way, public argumentation specifically serves the rule of law via the criticism of legal exercises of power, thus helping to reduce the number of arbitrary or unjustified instances.

Whether by appeal to universal or more particularised norms, public argumentation thus serves to foster "critical agency" in a society with regard to determining the priorities among primary social goods, the ends of government, and the legitimacy of political bodies (Ricoeur, 1992). Whether public argumentation requires distinct norms that are not shared with other kinds of argumentation-for instance norms concerning the preservation of value rather than of truth (Kock, 2013) — this we leave for another occasion.

\section{Opinion formation and decision making by individuals and small groups}

In smaller settings such as dialogical exchanges or "mini-public" deliberations, public argumentation can be viewed as serving the function of resolving, or at least engaging with, a difference of opinion (van Eemeren and Grootendorst 2004, 52-54; Walton 1990). These functions arise from viewing argument as externalizing a reasoning episode that leads from premises to conclusion(s), and as serving the various goals that characterize different dialogue types, e.g., persuasion dialogue (aka critical discussion) aimed at dispute resolution, inquiry aimed at solving a non-practical problem, negotiation aimed at a compromise agreement, eristic dialogue aimed at renewed emotional or intellectual hierarchy, information seeking dialogue aimed at a more even distribution of information, and deliberation aimed at solving a practical problem (Walton, 1990; Walton and Krabbe, 1995).

Specifically the dialogue type of a critical discussion has inspired the development of a normative model by the same name. Argumentation here serves to resolve conflicts of avowed opinions on the merits, by enabling the exchange of reasons in a mutual attempt to establish whether a thesis can withstand an opponent's critical testing (van Eemeren \& Grootendorst, 1984; Barth and Krabbe, 1982). Real-life argumentation can subsequently be viewed as serving the strategic maneuvering of individual arguers, in the sense of seeking to balance their dialectical objective to resolve a disagreement on the merits with their rhetorical objective to persuade the other side and thereby resolve the disagreement in their own favour (van Eemeren, 2010).

In specific institutional settings (e.g., parliament), strategic maneuvering often follows stereotypical patterns, patterns that can be explained by the purposes of the institution and the procedures/conventions operative in that setting (van Eemeren \& Garssen, 2014). For instance, when members of the European Parliament must determine whether a rapporteur's policy proposal merits 
acceptance, the institutional purpose typically "produces" specific combinations of arguments (e.g., reasoning from a policy effect and the effect's utility to the selection of that policy, in tandem with reasoning in support of the effect's utility). Oftentimes, argumentation here aims not only at rationally persuading opponents, but at the same time also at changing the institutional environment (Jackson 2015).

Next to specifying the functions of public argumentation in dialectical terms, it can also be specified epistemically. Whenever epistemic assets are distributed unequally, where agents are fallible and incentives to deceive are present, interpersonal argumentation should generally promote truth and avoid error, not only in cognitive inquiries but equally in practical settings that concern action or policy (Goldman, 1994). Argumentation can thus be viewed as a cooperative inquiry into the truth, truth-likeness or probability of some thesis, an inquiry that is based on critical checks as to whether the epistemically motivated truth- or adequacy-conditions of focal theses have been fulfilled (Lumer, 2005; Govier, 2018; Biro and Siegel, 2006). The standard function of acts of arguing can then be described as that of leading individual agents to entertain rationally justified beliefs (Lumer, 2005, 219; Goldman, 2003, 58; Siegel \& Biro, 1997, 278, 286; similarly: Feldman, 1999, xiii, 12, 24; Sinnott-Armstrong, 1999, 181; yet see Goodwin, 2007). Among the more distal functions for which acts of arguing are particularly apt are the following: representing the justification of beliefs, transferring justified beliefs to others, cognizing autonomously, reconsidering a belief, and securing a justified belief intersubjectively (Lumer, 2005, 219f.).

\section{Goals and functions pertaining to understanding}

This section presents goals and functions of public argumentation that relate to understanding. (Again, we leave a survey of relevant norms, such as Gricean maxims or norms governing assertion, to another occasion.) The practice of public argumentation may help to apprehend "wicked" practical issues, and can thus form a vehicle for understanding policy issues (Rodríguez-Alcázar, 2017). Generally, reason-based policy choices are more tractable to stakeholders, debaters or onlookers, than choices which enjoy no argumentative support. In this sense, public argumentation as an institutional praxis serves to establish, or increase, the transparency and accountability of policy decisions (Dryzek, 2010).

Participants within this practice have a plethora of devices at their disposal to increase their understanding regarding the issue at hand, as well as the standpoints, preferences, and justifications others bring forward. For example, they can variously define (Robinson, 1950), clarify or "precizate" (Naess, 1966), or dissociate (Perelman \& Olbrechts-Tyteca, 1969) the terms used to express arguments. As linguistic framing is indispensable to argumentation (Wohlrapp, 2014), how agents construe premises and conclusions typically conveys an evaluation, that may or may 
not be widely shared. Because a certain level of contestation serves to uphold the quality of public argumentation (Manin 2005; Mansbridge et al, 2010), the framing and reframing of policy issues to one's own advantage - for example by way of "persuasive" or "quasi definitions"- can in principle be part of a sound rhetorical strategy (Zarefsky, 2007).

The litigation of the meaning of concepts contested in public controversies (Ludlow, 2014) can also take place by means of meta-linguistic negotiations. Here, one participant challenges how another participant uses a term in one of her statements. Yet this occurs not by mentioning a key-term and explicitly disagreeing with its definition, but rather by allegedly "denying" the statement (Plunkett and Sundell, 2013). Those who participate in such metalinguistic negotiation need not be fully aware that they also engage in a linguistic (aka verbal) dispute, so that confusion may easily result. At the same time, public argumentation includes tools for gaining clarity about the relevant meanings of key-terms and possibly to reach an agreement on their use, which is instrumental to various of the goals and functions discussed in previous sections.

The intimate link between argumentation and the goal of mutual understanding allows for a critical perspective on perversions of this normative aim (Habermas, 1970; Bohman, 1986). A speaker may seek to obfuscate or mislead her peers or her audiences, for instance by making an issue appear unwarrantedly complex, by making her contributions ambivalent, ambiguous or vague, or by bringing in unjustifiable presuppositions and other kinds of implied meaning. Strategies of obfuscation and manipulation generally are more easily employed outside of a critical face-to-face dialogue, for instance when addressing large non-responsive audiences through mass or social media. These perversions may erode social equality (Saul, 2017b), serve false ideologies (Stanley, 2015), or create conditions that promote verbal strife or lead to an unlimited exercise of power. This makes them inimical to public argumentation. Examples include: utterances loaded with presuppositions (Langton, 2018), insinuations (Fricker, 2012), codewords, dog whistles and figleaves (Saul, 2017a), devices for manipulative propaganda (Stanley, 2015), and the exploitation of generic terms (Anderson, Haslanger and Langton, 2012).

In short, public argumentation may serve the understanding required by transparent and autonomous opinion formation and decision making, but it may equally prevent us from reaching this goal.

\section{Conclusion}

We have sketched a diverse range of goals and functions connected to the concept of public argumentation. This list is compiled from diverging disciplines, schools of thought, and types of literature. It shows the need to deal with the connections 
between goals and functions, respectively their absences. For example: Does extrinsic legal justification require agreement on epistemological principles? What else, if anything, is needed for a political decision to be justified if the decision is based on the way the stakeholders resolved their initial disagreements regarding the policy issue?

Most of the goals and functions we have listed are suggestive of norms by which to evaluate the quality of public argumentation. This shows that it is in principle worth investigating the connections between norms in light of the connections between goals and function. Yet at this stage, the norms themselves are not only implicit, they also look far from being simple. One would probably best analyze them as multidimensional constructs. In a subsequent paper, we hope to provide a survey of the norms for public argumentation, and to explain how they relate to public argumentation's goals and functions.

\section{References}

Alexy, R. (1989). A Theory of Legal Argumentation. Oxford: Oxford University Press.

Anderson, L., Haslanger, S., and Langton, R. (2012). Language and race. In: G. Russell \& D. Graff Fara (eds.), The Routledge Companion to Philosophy of Language (pp. 753-767). London: Routledge.

Arrow, K.J. (1951). Social Choice and Individual Values. Hoboken, NJ: John Wiley $\&$ Sons.

Barth, E.M. and E.C.W. Krabbe (1982). From Axiom to Dialogue: A Philosophical Study of Logics and Argumentation. Berlin, etc.: Walter de Gruyter.

Biro, J. \& H. Siegel (2006). In defense of the objective epistemic approach to argumentation. Informal Logic, 26, 91-101.

Bohman, J. F. (1986). Formal pragmatics and social criticism: The philosophy of language and the critique of ideology in Habermas's theory of communicative action. Philosophy and Social Criticism, 11, 331-353.

Bellamy, R. (2009). The republic of reasons: Public reasoning, depoliticization and non-domination. In: S. Besson, J.L. Marti (eds.), Legal Republicanism: National And International Perspectives (pp. 102-120). Oxford: Oxford University Press.

Benhabib, S. (1994). Deliberative rationality and models of democratic legitimacy. Constellations 1, 26-52.

Black, D. (1948). On the rationale of group decision-making. Journal of Political Economy. 56: 23-34

Bovens, M. D. Curtin, and P. 't Hart (Eds.) (2010). The real world of EU accountability: what deficit? Oxford: Oxford University Press. 
Chambers, S. (2009). Rhetoric and the public sphere: Has deliberative democracy abandoned mass democracy? Political Theory, 37 (3), 323-350.

Chambers, S. (2010). Theories of political justification. Philosophy Compass, 5 (11), 893-903.

Cooke, M. (2002). Argumentation and transformation. Argumentation, 16, 79-108.

Dryzek, J.S. (1983). Ecological rationality. International Journal of Environmental Studies, 21 (1), 5-10.

Dryzek, J.S. (2010). Rhetoric in democracy: A systemic appreciation. Political Theory, 38, 319-339.

Dryzek, J.S., and C. List (2003), Social choice theory and deliberative democracy: A reconciliation. British Journal of Political Science, 33 (1), 1-28

Van Eemeren, F.H. (2010). Strategic Maneuvering in Argumentative Discourse. Amsterdam: John Benjamins.

van Eemeren, F.H., et al. (2014). Handbook of Argumentation Theory. Dordrecht etc.: Springer.

van Eemeren, F. H., and B. J. Garssen (2014). Argumentative patterns in discourse. In: D. Mohammed D., and M. Lewinski (Eds.), Virtues of Argumentation: Proceedings of the 10th International Conference of the Ontario Society for the Study of Argumentation (OSSA), May 22-26, 2013 (pp. 1-15). Windsor, ON: OSSA.

van Eemeren, F.H., and R. Grootendorst (1984). Speech Acts in Argumentative Discussions. A Theoretical Model for the Analysis of Discussions Directed towards Solving Conflicts of Opinion. Dordrecht; Cinnaminson: Foris.

van Eemeren, F.H., and R. Grootendorst (2004). A Systematic Theory of Argumentation. The pragma-dialectical approach. Cambridge: Cambridge U.P.

Elster, J. (1998). Deliberative Democracy. Cambridge, MA: Cambridge UP.

Feldman, R.(1999). Reason and Argument. (2nd Edition.) Upper Saddle River, N.J.: Prentice-Hall.

Fishkin, J. (2009). When the People Speak. Deliberative Democracy and Public Consultation. Oxford: Oxford University Press.

Fraser, N. (1992). Rethinking the public sphere: A contribution to the critique of actually existing democracy. In: C. Calhoun (ed.), Habermas and the Public Sphere (pp. 109-142). Cambridge, MA: The MIT Press.

Fricker, E. (2012). I-stating and insinuating. Aristotelian Society Supplementary Volume, 86 (1), 61-94.

Gilbert, M.A. 1997. Coalescent Argumentation. Mahwah, NJ: Lawrence Erlbaum.

Goldman, A.I. (1994). Argumentation and social epistemology. The Journal of Philosophy, 91,27-49. 
Goldman, A.I. (2003). An epistemological approach to argumentation. Informal Logic, 23, 51-63.

Goodwin, J. (2007). Argument has no function. Informal Logic, 27, 69-90.

Govier, T. (2018). Problems in Argument Analysis and Evaluation (2nd ed.). Windsor, ON: Windsor Studies in Argumentation.

Habermas, J. (1970) Toward a Rational Society (Translation by: J. J. Shapiro). Boston: Beacon.

Habermas, J. (1996). Between Facts and Norms: Contributions to a Discourse Theory of Law and Democracy (Translation W. Rehg). Cambridge, MA: The MIT Press.

Hamblin, C.L. (1970). Fallacies. Newport News, VA: Vale Press.

Jackson, S. (2015). Design thinking in argumentation theory and practice. Argumentation, 29, 243-263.

Kjeldsen, J.E. (2015). The rhetoric of thick representation: How pictures render the importance and strength of an argument salient. Argumentation, 29, 197-215.

Kock, C. (2006). Multiple warrants in practical reasoning. In: D. Hitchcock and B.Verheij (eds.), Arguing on the Toulmin Model: New Essays in Argument Analysis and Evaluation (pp. 247-259). Dordrecht: Springer.

Kock, C. (2007). Norms of legitimate dissensus. Informal Logic, 27(2), 179-196.

Kock, C. (2013). Defining rhetorical argumentation. Philosophy \& Rhetoric, 46 (4), 437-464.

List, C. (2013). Social choice theory. In: E.N. Zalta (Ed.), The Stanford Encyclopedia of Philosophy. The Metaphysics Research Lab: Stanford, CA.

Langton, R. (2018). Blocking as counter-speech. In: D. Harris, D. Fogal, and M. Moss (eds.), New Work on Speech Acts (pp. 144-164). New York: Oxford University Press.

Lovett, F. (2018). Republicanism. In: E.N. Zalta (Ed.), The Stanford Encyclopedia of Philosophy. The Metaphysics Research Lab: Stanford, CA. https://plato.stanford.edu/archives/sum2018/entries/republicanism/ [accessed 21.10.2019]

Ludlow, P. (2014). Living Words: Meaning Underdetermination and the Dynamic Lexicon. Oxford: Oxford University Press.

Lumer, C. (2005). The epistemological theory of argument - how and why? Informal Logic, 25, 213-243.

Siegel, H., and Biro, J. (1997). Epistemic normativity, argumentation, and fallacies.Argumentation, 11, 277-292.

MacCormick, N. (2005). Rhetoric and the Rule of Law: A Theory of Legal Reasoning. Oxford: OUP.

Manin, B. (2005). Democratic deliberation: Why we should promote debate rather than discussion. Paper delivered at the Program in Ethics and Public Affairs 
Seminar, Princeton University, October $13^{\text {th }}$ 2005. Retrieved on August 27, 2019 , from:

https://as.nyu.edu/content/dam/nyu-as/faculty/documents/delib.pdf.

Mansbridge, J., J. Bohman, S. Chambers, D. Estlund, A. Follesdal, A. Fung, C. Lafont, B. Manin, and J.L. Martì (2010). The role of self-interest and the role of power in deliberative democracy. The Journal of Political Philosophy, 18, 64-100.

Mercier, H., and D. Sperber (2011). Why do humans reason? Arguments for an argumentative theory. Behavioral and Brain Sciences, 34 (2), 57.

Mohammed, D. (2016). Goals in argumentation: A proposal for the analysis and evaluation of public political arguments. Argumentation 30 (3): 221-245.

Mohammed, D. 2018. Argumentation in Prime Minister's Question Time. Accusations of inconsistency in response to criticism. Amsterdam: John Benjamins.

Mulgan, R. (2000). 'Accountability': An ever-expanding concept. Public Administration, 78 (3): 555-573.

Mulgan, R. (2004). Holding power to account: Accountability in modern democracies. London: Palgrave Macmillan.

Naess, A. (1966). Communication and Argument: Elements of Applied Semantics. (Translation A.Hannay). London: Allen \& Unwin.

Patterson, S. (2011). Functionalism, normativity and the concept of argumentation. Informal Logic, 31(1), 1-25.

Perelman, Ch. and L. Olbrechts-Tyteca (1969). The New Rhetoric: A Treatise on Argumentation. Notre Dame: University of Notre Dame Press.

Pettit, P. (1997). Republicanism: A Theory of Freedom and Government. Oxford: Clarendon Press.

Pivato, M. (2019). Realizing epistemic democracy. In: J.F. Laslier, H. Moulin, R. Sanver, and W.S. Zwicker (eds.), The Future of Economic Design (pp. $\mathrm{xx}-\mathrm{yy}$ ). Dordrecht, etc.: Springer (to appear).

Plunkett, D., and T.Sundell (2013). Disagreement and the semantics of normative and evaluative terms. Philosophers' Imprint, 13, 1-37.

Rawls, J. (2005). Political Liberalism (Expanded ed.). New York: Columbia University Press.

Ricoeur, P. (1992). Oneself as Another. (Translation K. Blamey.) Chicago: The University of Chicago Press.

Robinson, R. (1950). Definition. Oxford: Clarendon Press.

Rodríguez-Alcázar, J. (2017). Beyond realism and moralism: a defense of political minimalism. Metaphilosophy, 48 (5), 727-44.

Saul, J. (2017a). Racial figleaves, the shifting boundaries of the permissible, and the rise of Donald Trump. Philosophical Topics, 45 (2), 97-116. 
Saul, J. (2017b). Are generics especially pernicious? Inquiry (online first), DOI: 10.1080/0020174X.2017.1285995.

Schedler, A. (1999). Conceptualizing accountability. In: A. Schedler, L. Diamond, and M.F. Plattner (eds.) The Self-Restraining State: Power and Accountability in New Democracies (pp. 13-28). Boulder and London: Lynne Riener Publishers.

Siegel, H., and J. Biro (1997). Epistemic normativity, argumentation, and fallacies. Argumentation 11, 277-292.

Sinnott-Armstrong, W. (1999). Begging the question. Australasian Journal of Philosophy 77, 174-191.

Stanley, J. (2015). How Propaganda Works. Princeton, NJ: Princeton University Press.

Sunstein, C. (1993). The Partial Constitution. Cambridge, MA: Harvard University Press.

Tsai, L.L. (2011). Accountability. In: G. T. Kurian (ed.), The Encyclopedia of Political Science, (pp. 5-9). Thousand Oaks, etc.: Sage.

Vallier., K. (2018). Public justification. In: E.N. Zalta (Ed.), The Stanford Encyclopedia of Philosophy. The Metaphysics Research Lab: Stanford, CA. https://plato.stanford.edu/archives/sum2018/entries/republicanism/ [accessed 21.10.2019]

Walton, D. N. (1990). What is reasoning? What is an argument? The Journal of Philosophy, 87 (8), 399-419

Walton, D., and E.C.W. Krabbe. (1995). Commitment in dialogue: Basic concepts of interpersonal reasoning. Albany: SUNY Press.

Williams, B. (2005). In the Beginning Was the Deed: Realism and Moralism in Political Argument. Princeton, NJ: Princeton University Press.

Wohlrapp, H. (2014). The Concept of Argument. Dordrecht: Springer.

Wolterstorff, N. (2012). Understanding liberal democracy: Essays in political philosophy. Oxford: Oxford University Press.

Wróblewski, J. (1971). Legal decision and its justification. Logique et Analyse, 14 (53/54), 409-419.

Zarefsky, D. (2007). Strategic maneuvering through persuasive definitions: Implications for dialectic and rhetoric. Argumentation, 20, 399-416. 